Ensino, Saúde e Ambiente - V5 (2), pp. 211-221, ago. 2012

\title{
EDUCAÇÃO AMBIENTAL NOS ANOS FINAIS DO ENSINO FUNDAMENTAL EM UMA ESCOLA DO CAMPO: UMA ANÁLISE A PARTIR DO PROJETO POLÍTICO PEDAGÓGICO
}

\section{ENVIRONMENTAL EDUCATION IN THE LAST YEARS OF ELEMENTARY EDUCATION IN A RURAL SCHOOL: AN ANALYSIS FROM THE POLITICAL PEDAGOGICAL PROJECT}

\author{
Talita Mazzini Lopes ${ }^{1}$; Maria Cristina de Senzi Zancul ${ }^{2}$ \\ ${ }^{1}$ Faculdade de Ciências e Letras de Araraquara, UNESP/ Departamento de Ciências da Educação/ \\ talita_lopes6@yahoo.com.br \\ ${ }^{2}$ Faculdade de Ciências e Letras de Araraquara, UNESP/ Departamento de Ciências da Educação/ \\ mczancul@fclar.unesp.br
}

\section{RESUMO}

A Educação Ambiental (EA), elemento crítico para o enfrentamento da crise ambiental, deve estar presente na educação formal de maneira contínua, permanente e transversal. Pesquisas apontam, no entanto, que o trabalho com a EA ocorre, muitas vezes, de maneira esporádica e descontínua e está vinculado, principalmente, à disciplina Ciências. O objetivo deste estudo foi investigar como se dá a inserção da temática ambiental no Projeto Político Pedagógico (PPP) de uma escola do campo, do município de Araraquara-SP. Por meio da análise documental do PPP foram examinadas as propostas referentes à Educação Ambiental para os anos finais do ensino fundamental. Os resultados permitiram compreender, de forma complexa e contextualizada, aspectos relevantes da inserção da temática ambiental no currículo escolar e revelam que as sugestões para os trabalhos com o tema Meio Ambiente, atendem, em linhas gerais às recomendações da conferência de Tblisi e às orientações dos Parâmetros Curriculares Nacionais (PCN).

Palavras-chave: Educação ambiental; práticas pedagógicas; ensino fundamental; projeto político pedagógico.

\begin{abstract}
Environmental education (EE), a critical component to face the environmental crisis, must be present in formal education in a continuous, permanent and transversal way. Studies show, however, that EE occurs, often, in a sporadic and discontinuous way, and that it is mainly linked to Sciences. The objective of this study was to investigate the inclusion of environmental subjects in the Political Pedagogical Project (PPP) of a rural school, in Araraquara, SP. Through documentary analysis of the PPP, proposals for the Environmental Education for the last years of elementary education were examined. The results allowed the understanding, in a complex and contextualized way, of aspects related to the presence of environmental subjects in the school curriculum. They reveal that the suggestion of working with Environment attend the recommendations of the conference of Tbilisi and of Brazilian National Curriculum (PCN).
\end{abstract}

Key-words: Environmental education; pedagogical practices; elementary education; political pedagogical project. 


\section{INTRODUÇÃO}

A sobrevivência humana sempre esteve ligada ao meio natural, entretanto, o crescimento abrupto da população mundial, associado à transição para o sistema capitalista de produção que incentiva o consumo desenfreado de produtos e o descarte sem reflexões, aumentou a pressão sobre os recursos naturais e sobre o meio ambiente.

A crise ambiental e social, gerada pelo atual modelo econômico e por formas inadequadas de lidarmos com a natureza, têm motivado a proposição de vários encontros internacionais, com o objetivo de discutir as questões que se apresentam nesse campo, em busca de propostas concretas que contribuam para a construção de sociedades mais sustentáveis.

Segundo os Parâmetros Curriculares Nacionais (BRASIL, 1997), os dilemas e constatações apontados nessas reuniões têm recomendado que se invista numa mudança de mentalidade, conscientizando as comunidades para a necessidade de adotarem novos pontos de vista e novas atitudes.

Foi na Conferência de Estocolmo, realizada em 1972 na Suécia, que a Educação Ambiental (EA) foi reconhecida, pela primeira vez, como elemento crítico para o combate à crise ambiental do mundo. Os objetivos, as funções, as estratégias, as características, os princípios e as recomendações para a EA só foram definidos, entretanto, na Conferência de Tbilisi, realizada em 1977 na Geórgia (PEDRINI, 2001).

De acordo com essa conferência, a EA deveria: basear-se na ciência e tecnologia para a consciência e adequada apreensão dos problemas ambientais; estar presente tanto na educação formal como na informal; despertar o indivíduo a participar ativamente na solução de problemas ambientais do seu cotidiano; ser permanente, global e sustentada numa base interdisciplinar (PEDRINI, 2001).

Para Dias (2004),

[...] a Educação Ambiental teria como finalidade promover a compreensão da existência e da importância da interdependência econômica, política, social e ecológica da sociedade; proporcionar a todas as pessoas a possibilidade de adquirir conhecimentos, o sentido dos valores, o interesse ativo e as atitudes necessárias para proteger e melhorar a qualidade ambiental; induzir novas formas de conduta nos indivíduos, nos grupos sociais e na sociedade em seu conjunto, tornando-a apta a agir em busca de alternativas de soluções para os seus problemas ambientais, como forma de elevação da sua qualidade de vida (p.83).

De acordo com a Política Nacional do Meio Ambiente (Lei Nº 6.938/81), a EA deve acontecer tanto no âmbito formal, quanto no âmbito não formal. Por envolver problemáticas sociais atuais e urgentes, consideradas de abrangência nacional e até 
mesmo mundial, o tema meio ambiente foi incorporado aos currículos das áreas e deve ser tratado de maneira contínua, permanente e transversal, em toda sua complexidade. Esse tema não deve estar restrito à abordagem de uma única área, nem se constituir em uma área ou disciplina específica no currículo (BRASIL, 1998).

A transversalidade diz respeito à possibilidade de se estabelecer, na prática educativa, uma relação entre aprender conhecimentos teoricamente sistematizados (aprender sobre a realidade) e as questões da vida real e de sua transformação (aprender na realidade e da realidade). E a uma forma de sistematizar esse trabalho e incluí-lo explícita e estruturalmente na organização curricular, garantindo sua continuidade e aprofundamento ao longo da escolaridade (BRASIL, 1998, p 30).

Apesar da expansão e da universalização da EA, pesquisas apontam, que nas escolas, essa prática não tem ocorrido conforme as recomendações existentes, já que, em muitos casos, ainda está vinculada, principalmente, à disciplina Ciências (Viveiro Ruy, 2006; Nascimento, 2006; Pereira, 2007), ocorrendo de maneira esporádica, descontínua e pontual (Ribeiro, 2004; Vasconcelos, 2008, Ferrari, 2009).

A partir dos resultados de tais pesquisas, percebemos que existem barreiras para a inclusão do tema meio ambiente de forma transversal nas escolas. $\mathrm{O}$ estudo realizado por Ferrari (2009), ao investigar a inserção da temática ambiental em escolas municipais da cidade de Araraquara - SP apontou algumas dificuldades identificadas pelos professores para o desenvolvimento desse tema de forma mais abrangente:

[...] a falta de colaboração da equipe pedagógica das unidades escolares no desenvolvimento de um projeto temático interdisciplinar e transversal e, consequentemente, o isolamento das atividades em Educação Ambiental nas próprias disciplinas/áreas de seus propositores; a falta de tempo para preparar, organizar e executar os projetos em Educação Ambiental, sem que corram os atropelos, pela necessidade de dar conta dos conteúdos curriculares obrigatórios (FERRARI, 2009, p.156).

O trabalho de Viveiro Ruy (2006, p.8), sobre como a EA é tratada nas escolas de ensino fundamental e médio da cidade de São Carlos - SP, constatou que a abordagem utilizada nas atividades/projetos intitulados de Educação Ambiental,

[...] insere-se em uma perspectiva simplista, do tipo preservacionista, associada ao ensino tradicional, com práticas estereotipadas e desprovidas de fundamentação didática, centrada na responsabilidade individual e incapaz de provocar nos educandos questionamentos mais profundos sobre o sistema e as ideologias que o regem, em detrimento de sua potencialidade educacional transformadora.

Consideramos que para uma mudança de comportamento dos indivíduos e a consequente transformação social, é essencial que a EA esteja baseada numa ação crítica e emancipatória. Esse tipo de ação, de acordo com Loureiro (2006) se conjuga "no diálogo, no exercício da cidadania, no fortalecimento dos sujeitos, na superação das 
formas de dominação capitalistas e na compreensão do mundo em sua complexidade e da vida em sua totalidade" (p.24), sempre levando em consideração as condições culturais, econômicas e políticas nas quais os indivíduos estão inseridos.

Para Leff (2006), a emancipação representa a libertação da hipereconomização do mundo e da ideologia dominante, que nos faz desejar em função do que determinam o poder da tecnologia e o mercado. Isso implica ressignificar alguns princípios da moral política esmagados pelo liberalismo político e econômico, como fraternidade, liberdade e igualdade.

Diante do exposto e da relevância da inclusão da temática ambiental no currículo escolar, buscamos investigar como o tema meio ambiente está inserido no Projeto Político Pedagógico de uma unidade escolar da cidade de Araraquara (SP), especificamente uma escola do campo e quais as propostas para o trabalho com essa temática.

\section{OBJETIVOS}

Considerando que o Projeto Político Pedagógico (PPP) da unidade escolar é um orientador da prática docente, este trabalho tem como objetivo averiguar a inserção da temática ambiental nos anos finais do Ensino Fundamental em uma escola de campo da cidade de Araraquara-SP, verificando se as propostas de trabalho formuladas estão de acordo com as recomendações das conferências sobre EA e com as sugestões dos Parâmetros Curriculares Nacionais (PCN).

O presente trabalho faz parte de uma pesquisa mais ampla, cujo objetivo é conhecer como a EA vem sendo trabalhado no âmbito escolar, através da análise das práticas pedagógicas de duas escolas municipais da cidade de Araraquara-SP.

\section{METODOLOGIA}

A investigação segue os princípios da pesquisa qualitativa que, de acordo com Ludke e André (1986, p.18), "se desenvolve numa situação natural, é rico em dados descritivos, tem um plano aberto e flexível e focaliza a realidade de forma complexa e contextualizada".

Para a coleta de dados da etapa descrita nesse trabalho, foi feita a análise documental do PPP da escola de campo selecionada, a fim de verificar as propostas referentes à Educação Ambiental contidas nele.

De acordo com Bogdan e Biklen (1994), por meio dos documentos oficiais “os investigadores podem ter acesso à "perspectiva oficial”, bem como às várias maneiras 
como o pessoal da escola comunica", o que permite "a compreensão de como a escola é definida por várias pessoas" (p.180), focando, assim, a realidade de forma complexa e contextualizada.

É importante ressaltar que esse trabalho delineia apenas uma das etapas realizadas na pesquisa e que foram utilizados outros instrumentos de coleta de dados específicos das abordagens qualitativas, como entrevistas, análise documental dos Planos de Ensino dos professores e observação direta das atividades desenvolvidas, que não serão referidos nesta oportunidade.

\section{RESULTADOS E DISCUSSÃO}

Situada na agrovila de um assentamento rural que ocupou as terras da fazenda de uma usina de cana-de-açúcar existente na cidade, desapropriadas oficialmente em 1989 pelo Instituto Nacional de Colonização de Reforma Agrária (INCRA), a escola do campo selecionada para a pesquisa atende apenas educandos residentes no campo e no assentamento. Em virtude da precária estrutura, da localização e dos pouquíssimos recursos de transporte, os moradores do assentamento não têm muito acesso à cultura e ao lazer, que é proporcionado, muitas vezes, apenas pelo ambiente escolar.

A leitura e análise do Projeto Político Pedagógico desta unidade escolar foram relevantes, para compreender, de forma complexa e contextualizada, não apenas aspectos relacionados à inserção da temática ambiental no ambiente escolar, mas também à realidade e ao funcionamento da escola.

As informações, que estão descritas nesse trabalho, dizem respeito aos seguintes aspectos: princípios e fins da educação; finalidades e objetivos da escola; missão e valores; organização curricular; projetos sugeridos; gestão escolar.

Com base na Constituição de 1988, no Estatuto da Criança e do Adolescente de 1990 e na Lei de Diretrizes e Bases da Educação Nacional de 1996, a escola do campo elegeu dez princípios e fins da educação que buscam a formação cidadãos críticos, capazes de atuar na sociedade e na realidade em que vivem.

Dentre esses princípios destacamos dois que fazem alusão direta à questão ambiental, quais sejam: espaços e tempos alternativos de educação (que pretende utilizar os espaços verdes do entorno da escola); integração e interação com o meio ambiente e conscientização ecológica. Assim, além da preocupação com a identidade, com a cultura e com o pertencimento ao campo, a proposta pedagógica da escola também explicita sua preocupação com a utilização de espaços naturais como 
laboratórios de aprendizagem, de forma que os educandos e a comunidade valorizem o meio ambiente natural, estimulando uma relação saudável do homem com o meio ambiente, de forma que ele venha a adquirir uma consciência crítica com relação às questões ambientais.

As finalidades e objetivos da escola apontados no PPP 2011-2013 vão ao encontro dos princípios elencados já que são “inspirados numa educação libertária, humanizadora fortalecida pelo amor", visando o desenvolvimento pleno do ser humano e a formação básica do cidadão. Nesse sentido, segundo o PPP, a escola procura desenvolver uma educação de qualidade que propicie aos indivíduos a "aquisição de conhecimentos, habilidades e formação de atitudes e valores (o fortalecimento dos vínculos de família, dos princípios de liberdade e solidariedade humana)", mediante a "compreensão do ambiente natural, cultural e social, do sistema político, da tecnologia, das artes e dos valores em que se fundamenta a sociedade" (PPP, 2011-2013, p.13).

Com relação à missão e valores assumidos pela escola, o documento apresenta doze valores que devem permear a educação do campo, quais sejam: "respeito, compreensão, paz, equilíbrio, alegria, autoestima, determinação, esperança, união, fé, solidariedade e responsabilidade" (PPP, 2011, p.16 e 19). O PPP ressalta que os valores humanizadores são "a base e o sustentáculo" do projeto.

Ainda de acordo com o texto, o currículo do Ensino Fundamental se organiza a partir de um grande tema gerador "a mãe Terra e seus respectivos complexos temáticos" que são "subtemas significativos" sobre a realidade dos alunos (PPP, 2011).

Esses subtemas, abordados pelos complexos temáticos são: identidade; meio ambiente e trabalho; saúde; ética e política. No Ensino Fundamental I ( $1^{\circ}$ ao $5^{\circ}$ ano) todos os complexos devem ser tratados ao longo dos bimestres.

No Ensino Fundamental II, foco de análise desse trabalho, cada ano escolar deve trabalhar um complexo temático. Eles se distribuem da seguinte maneira nos diferentes anos: $6^{\circ}$ ano - Complexo temático "Identidade", sob a responsabilidade das disciplinas História, Arte e Matemática; $7^{\circ}$ ano - Complexo temático "Meio Ambiente e Trabalho", a cargo das disciplinas Geografia e Língua Portuguesa; $8^{\circ}$ ano - Complexo temático "Saúde", sob a responsabilidade das disciplinas Ciências e Educação Física; 9 ” ano - Complexo temático "Ética e Política", sob o encargo das disciplinas Filosofia e Inglês.

Embora o complexo temático "Meio Ambiente e Trabalho" seja proposto apenas para o $7^{\circ}$ ano, é importante ressaltar que nos demais complexos também estão 
previstas atividades com conteúdos relacionados à temática ambiental que incluem aspectos culturais, históricos, sociais e políticos da realidade dos alunos. Outro fato a destacar é a possível interdisciplinaridade que pode ocorrer no trabalho com os complexos, uma vez que eles envolvem mais de uma disciplina curricular.

Ainda sobre a organização curricular, a análise do PPP nos permitiu obter informações sobre os projetos realizados pela escola. Ao todo são desenvolvidos quatro projetos, a saber: Projeto Plantando e Vivenciando Valores na Escola; Projeto Leitura; Projeto de Acolhida, Recepção e Comunicação; Projeto de Educação Ambiental.

O "Projeto Plantando e Vivenciando Valores na Escola", tem como objetivo provocar uma reflexão sobre os doze valores elegidos, já descritos anteriormente, de forma que a comunidade escolar, através da sensibilização e conscientização, possa repensar sobre suas atitudes e posturas, contribuindo, assim, para a transformação da sua realidade social e para a boa convivência e o "bem-estar" dos alunos, professores e funcionários da unidade escolar (PPP, 2011).

De acordo com o PPP, essa reflexão deve ser propiciada por meio de diálogos, leitura de textos informativos, confecção de cartazes, dinâmicas de grupo, teatros, músicas interativas, jogos e jogral tanto na Educação Infantil como no Ensino Fundamental I e II.

O "Projeto Leitura" busca incentivar esse hábito nos alunos e na comunidade, proporcionando, assim, a construção do conhecimento, a formação e informação dos indivíduos, bem como a aquisição de patrimônio cultural pelos assentados. Um dos objetivos desse projeto é a inserção social dos indivíduos, permitindo o acesso a outras atividades culturais e preparando para o pleno exercício da cidadania (PPP, 2011).

O "Projeto de Acolhida, Recepção e Comunicação", por sua vez, pretende sensibilizar os alunos sobre "a importância da acolhida, do cuidado, da comunicação e da receptividade" a todas as pessoas que chegam à escola, tais como, "membros da comunidade, estagiários/as, visitantes e outras escolas" que desejem conhecer e contribuir com o PPP da escola do campo, bem como a todos aqueles que fazem parte da comunidade escolar (PPP, 2011, p.102).

Dentre os objetivos do projeto, destaca-se: "fazer com que os/as educandos/as percebam que o cuidado, o amor e o carinho são virtudes que devem fazer parte de toda a nossa vida, para que possamos conviver bem em sociedade" (PPP, 2011, p.102).

Por fim, o "Projeto de Educação Ambiental", desenvolvido na Educação Infantil e no Ensino Fundamental I e II, está dividido em cinco subprojetos intitulados: 
"Estudo do meio" (Educação Infantil e no $1^{\circ}$ ano), "Horta" ( $2^{\circ}$ e $3^{\circ}$ anos), "Plantas Medicinais" ( $4^{\circ}$ e $5^{\circ}$ anos) "Viveiro de Mudas" ( $6^{\circ}$ e $7^{\circ}$ anos) e "Agroecologia/Horta" $\left(8^{\circ}\right.$ e $9^{\circ}$ anos). As características e objetivos dos subprojetos desenvolvidos nos anos finais do Ensino Fundamental estão descritos a seguir.

O subprojeto de EA "Viveiro de Mudas", realizado em parceria com o SENAR (Serviço Nacional de Aprendizagem Rural), ITESP (Fundação Instituto de Terras do Estado de São Paulo) e INCRA (que fornecem informações técnicas e específicas sobre o tema), é interdisciplinar aos conteúdos das disciplinas Matemática, Geografia e Ciências, e tem a intenção de envolver as pessoas da comunidade, com o intuito de favorecer a troca de conhecimento, buscando alternativas sustentáveis para a comunidade local e agricultura familiar (PPP, 2011).

De acordo com o PPP, os objetivos desse subprojeto são:

Desenvolver a importância, a responsabilidade, o cuidado e a conservação das sementes como patrimônio da humanidade [...]; promover o desenvolvimento das habilidades cognitivas, sensoriais, motoras e sociais; ser um processo de educação coletiva, criando um espaço de auto-formação, de reflexão, de aprendizagem, fazendo com que o ambiente educativo da escola envolva os educandos, educadores e também a comunidade em sua construção; levar o aluno a identificar os diferentes ecossistemas pertencentes ao local do qual fazem parte; mostrar aos educandos a importância em se preservar/conservar o ambiente natural onde vivem; desenvolver a sensibilidade e a consciência ecológica nos educandos; estudar o local a ser reflorestado; selecionar as mudas adequadas para a área; realizar o plantio das mudas e acompanhar o crescimento" (PPP, 2011, p.95 e 96).

De acordo com o PPP (2011) este subprojeto é necessário, pois por meio dele pode-se desenvolver um estudo mais sistematizado do meio ambiente local.

O subprojeto "Agroecologia/Horta", com características semelhantes ao anterior, também deve ser trabalhado de forma sistematizada nas aulas das diferentes disciplinas curriculares, com uso de textos e vídeos informativos, cartazes e fotos ilustrativas, livros paradidáticos e por meio da coleta de dados e informações tanto dentro como fora do ambiente escolar (na agrovila e nos lotes). Os objetivos desse subprojeto estão assim definidos:

Fazer com que o/a educando/a reconheça o trabalho e a produção do ambiente em que vive; valorizar, a partir do estudo sistematizado, a produção agrícola e pecuária; valorizar o papel do homem do campo na construção e manutenção de uma sociedade justa; proporcionar o conhecimento de novas técnicas agrícolas para o uso nos lotes; recuperar o solo da horta; atuar na divulgação junto à comunidade escolar e através de atividades acadêmicas, os valores da cultura do campo e a importância dos alimentos sem agrotóxicos; construir uma composteira; trabalhos interdisciplinares, vivenciando os valores, tendo como tema Trabalho e Cooperação (PPP, 2011, p.97). 
Como pudemos observar pela análise do PPP, a temática ambiental deve ser abordada em todos os anos escolares por meio de projetos que pretendem ser interdisciplinares. Além disso, é importante ressaltar que os demais projetos que devem ser desenvolvidos pela escola do campo, embora não tratem diretamente da temática ambiental, focalizam a vivência e a reflexão de valores humanizadores e a construção de um cidadão que participe da transformação da realidade em que está inserido, objetivos estes coincidentes com os de uma EA crítica. As propostas de trabalho apresentadas no PPP procuraram atender aos princípios da transversalidade, recomendado pelos PCN para o trabalho com Meio Ambiente.

Ao avaliarmos as estratégias de ensino, percebemos também que elas estão de acordo com as recomendações dos PCN (BRASIL, 1998, p. 41), que apontam os projetos como "uma das formas de organizar o trabalho didático, que pode integrar diferentes modos de organização curricular". Segundo o documento, a organização dos conteúdos em torno de projetos, como forma de desenvolver atividades de ensino e aprendizagem, favorece a compreensão da multiplicidade de aspectos que compõem a realidade, uma vez que permite a articulação de contribuições de diversos campos de conhecimento.

Além disso, a ideia de trabalhar a EA por meio de projetos parece ser atraente aos professores. Ao investigar como as escolas da rede municipal de ensino do município de Araraquara-SP inserem a temática ambiental em seus PPP, Ferrari (2009), observou que professores e coordenadores pedagógicos consideram os projetos como a melhor maneira de se realizar uma ação eficiente em EA nas unidades escolares.

Da análise do PPP verificamos, ainda, a expectativa de que o princípio "Gestão democrática - participação da comunidade na tomada de decisões", elegido pela escola do campo, seja assegurado por meio de mecanismos de participação coletiva de toda a comunidade, tais como o Conselho de Escola, a Associação de Pais e Mestres e o Grêmio Estudantil.

A gestão escolar democrática parece ter estado presente na própria elaboração do PPP que, de acordo com o documento, contou com a participação de diversos atores, entre os quais a Secretaria Municipal de Educação, professores, pesquisadores de universidades públicas e particulares, técnicos do INCRA e do ITESP e militantes do MST, além de representantes dos alunos e da comunidade (PPP, 2011).

Ferreira (2001) ressalta que, para que as responsabilidades assumidas pela escola e pela educação se concretizem, é necessário que a direção escolar se construa e 
se legitime na participação, no exercício da democracia e na competência da construção coletiva do PPP, que deve refletir o projeto de homem e da sociedade que se quer.

Ainda, de acordo com a autora, é a partir da construção coletiva do PPP que os objetivos do conhecimento emancipatório serão atingidos, já que só assim a viabilidade e a concretização desse projeto estarão garantidas. Se todos estiverem convictos do indivíduo que querem formar para a sociedade que desejam construir, serão capazes de trabalhar para essa construção.

\section{CONCLUSÕES}

A análise do Projeto Político Pedagógico da escola de campo permitiu constatar que a preocupação com a temática ambiental se faz presente em toda a proposta pedagógica da escola, perpassando desde os princípios e fins da educação desta unidade escolar até sua organização curricular. Segundo o PPP, Meio Ambiente deve ser trabalhado por meio dos complexos temáticos e nos projetos formulados para todos os anos do Ensino Fundamental II.

De acordo com o documento analisado, os temas ambientais são abordados a partir da realidade dos alunos, levando em consideração as condições culturais, econômicas e políticas nas quais essa comunidade escolar está inserida, sempre buscando valorizar e resgatar a identidade e a cultura do trabalhador do campo.

É importante ressaltar que o texto do PPP revela uma preocupação com a formação de um cidadão crítico, apto a participar ativamente na solução dos problemas de sua comunidade, enfatizando a importância da conscientização, da sensibilização e da vivência de valores humanizadores, como o amor, a solidariedade e liberdade. Neste sentido, percebemos que a proposta se aproxima dos princípios da EA crítica e emancipatória.

Pela análise realizada, e considerando o PPP como um orientador da prática docente, verificamos que a temática ambiental está inserida nessa escola de maneira efetiva, contínua e interdisciplinar. As recomendações para os trabalhos com o tema Meio Ambiente procuram envolver toda a comunidade e, em linhas gerais atendem às recomendações da conferência de Tblisi e às sugestões dos PCN.

\section{REFERÊNCIAS BIBLIOGRÁFICAS}

BOGDAN, R. C.; BIKLEN, S. K. Investigação Qualitativa em Educação: Uma introdução à teoria e aos métodos. Porto Editora, 1994. 
BRASIL. Secretaria de Educação Fundamental. Parâmetros Curriculares Nacionais: introdução aos parâmetros curriculares nacionais. Secretaria de Educação Fundamental. Brasília: MEC/SEF, 1997. 172 p. Disponível em:

$<$ ftp://ftp.fnde.gov.br/web/pcn/05_08_introducao.pdf > Acesso em: 10 de agosto de 2008.

BRASIL. Secretaria de Educação Fundamental. Parâmetros curriculares nacionais: terceiro e quarto ciclos: apresentação dos temas transversais. Secretaria de Educação Fundamental. Brasília: MEC/SEF, 1998. 436 p. Disponível em: $\langle$ http://www.cdcc.sc.usp.br/CESCAR/Material_Didatico/ttransversais.pdf > Acesso em: 14 de agosto de 2008.

DIAS, G. F. Educação Ambiental: princípios e práticas. 9ª ed. São Paulo: Gaia, 2004.

FERRARI, A. H. Educação ambiental em escolas de ensino fundamental da rede municipal de Araraquara: do projeto político-pedagógico à sala de aula. 2009. 221 f. Dissertação (Mestrado em Educação escolar) - Universidade Estadual Paulista, Faculdade de Ciências e Letras, Campus de Araraquara, Araraquara - SP, 2009.

FERREIRA, N. S. C. (org). Gestão Democrática da Educação: atuais tendências, novos desafios. São Paulo: Cortez, 2001.

LEFF, H. Racionalidade Ambiental: a reapropriação social da natureza. Rio de Janeiro: Civilização Brasileira, 2006.

LOUREIRO, C. F. B. Trajetória e Fundamentos da Educação Ambiental. $2^{a}$ ed. São Paulo: Cortez, 2006.

LÜDKE, M; ANDRÉ, M. E. D. A. Pesquisa em Educação: Abordagens Qualitativas. São Paulo: EPU, 1986.

NASCIMENTO, T. G. A Educação ambiental em escolas particulares de Campo Grande - Mato Grosso do Sul, na ordem jurídica vigente. 2006. Dissertação (Mestrado em Meio Ambiente e Desenvolvimento Regional). [Abstract]. Universidade para o Desenvolvimento do Estado e da Região do Pantanal, Campo Grande - MS.

PEDRINI, A. de G. (org.). Educação Ambiental: reflexões e práticas contemporâneas. $4^{\mathrm{a}}$ ed. Petrópolis: Vozes, 2001.

PEREIRA, K. A. B. Educação ambiental em uma escola agrícola de Campo Grande - MS: que saberes e que resultados. 2007. Dissertação (Mestrado em Educação). [Abstract]. Universidade Católica Dom Bosco, Campo Grande - MS.

RIBEIRO, A. L. R. Educação ambiental no espaço escolar: uma prática pedagógica a resignificar?. 2004. Dissertação (Mestrado em Desenvolvimento Regional e Meio Ambiente). [Abstract]. Universidade Estadual de Santa Cruz, Ilhéus - BA. VASCONCELOS, M. A. de O. Caracterização da prática da educação ambiental nas escolas de Aracaju. 2008. Dissertação (Mestrado em Desenvolvimento e Meio Ambiente). [Abstract]. Fundação Universidade Federal de Sergipe, São Cristóvão - SE. VIVEIRO RUY, R. A. A Educação Ambiental em escolas de ensino fundamental e médio do município de São Carlos - SP. 2006. 103 f. Dissertação (Mestrado em Educação - Núcleo Temático: Educação Ambiental) - Instituto de Biociências, Universidade Estadual Paulista, Rio Claro, 2006. Disponível em: $<$ http://www.athena.biblioteca.unesp.br/exlibris/bd/brc/33004137064P2/2006/ruy rav me rcla.pdf> Acesso em: 21 de agosto de 2010. 